\title{
La cuestión de la vida buena: una aproximación indirecta
}

\author{
EDUARDO FERMANDOIS* \\ Pontificia Universidad Católica de Chile (Chile) \\ efermanm@uc.cl
}

\begin{abstract}
Resumen
Dada la renovada vigencia que la antigua pregunta socrática: ¿cómo se debería vivir? goza en nuestros días —en particular, en el ámbito anglosajón y alemán-, no extraña que los diferentes enfoques vengan acompañados a menudo por consideraciones de índole metodológica. ¿Cómo abordar hoy la proverbial pregunta? ¿Con qué criterios de corrección debería cumplir una teoría de la vida buena? ¿Es siquiera posible una tal teoría? El propósito de la presente reflexión es contribuir al esclarecimiento de estas cuestiones mediante lo que propongo llamar una aproximación indirecta a la cuestión de la vida buena. En el texto se describen y justifican los rasgos centrales de dicha aproximación, la que se distancia del debate actual entre teorías de la vida buena, al no asumir una serie de pretensiones metodológicas características de dicho debate.
\end{abstract}

Palabras clave: vida buena, teorías de la vida buena, pregunta socrática, neutralidad, argumentación, explicación, descripción densa.

\section{The question of the good life: an indirect approach}

\begin{abstract}
Given the renewed interest that the old Socratic question "How should we live?" has taken in the present day -in particular, in the Anglo-Saxon and in the German world-it is not surprising that the different approaches are often accompanied by methodological considerations. How to deal with the old question today? What correction criteria should a theory of the good life meet? Is such a theory even possible? The aim of this essay is to contribute to the clarification of these issues through what I propose to call "an indirect approach" to the question of the good life. The paper describes and justifies the central features of this approach, which distances itself from the current debate between good life theories, by not assuming a series of methodological claims characteristic of this debate.
\end{abstract}

Key words: good life, good life theories, Socratic question, neutrality, argumentation, explanation, thick description.

* Doctor en Filosofía por la Universidad Libre de Berlín, Alemania. Autor de Sprachspiele, Sprechakte, Gespräche. Eine Untersuchung der Sprachpragmatik (2000).

La investigación que se decanta en este texto ha contado con un apoyo económico por el que agradezco aquí expresamente. Los datos correspondientes son: CONICYT (Comisión Nacional de Investigación Científica y Tecnológica), Programa FONDECYT REGULAR, Proyecto $N^{\circ}$ 1161716: “Amor y veracidad como aspectos de una vida buena. Contribuciones a la reflexión analítica sobre la vida buena". 
Sabio como te has vuelto, con tanta experiencia, habrás comprendido ya lo que significan las Ítacas.

Kavafis

I.

Fue hace ya unas tres décadas que la pregunta socrática: ¿cómo se debería vivir? ? $^{1}$ comenzó a resonar con fuerza en el medio filosófico anglosajón, lo mismo que en el alemán. Una serie de libros - los de Williams (1985), Griffin (1986), Sumner (1996), Seel (1995) y Wolf (1999), por nombrar apenas algunos- fueron dando lugar a lo que Steinfath denominó en su momento "un asombroso renacimiento" (1998: 7) de la proverbial pregunta $^{2}$. El impulso que dio lugar a este "regreso de la ética de la vida buena" (Seel, 1991: 42) no ha decaído en el tiempo más reciente, antes bien todo lo contrario; así queda de manifiesto en al menos una docena de monografías aparecidas en los últimos doce años, en diversas compilaciones y una ingente cantidad de artículos especializados ${ }^{3}$. Tampoco parece tratarse de la mera reactivación de un viejo tema: el surgimiento de problemáticas genuinamente nuevas en ámbitos distintos de la ética tradicional, como la filosofía de la religión, la filosofía política o la ética aplicada (Hoesch, Muders \& Rüther, 2013: 2s), así como la propuesta de originales distingos, programas y estrategias, parecen apuntar más bien a una auténtica renovación. Pero posea o no tal diagnóstico asidero suficiente, lo cierto es que la pregunta por una vida lograda o feliz, asunto capital de la filosofía que más de un autor o autora concibe como su principal motivación (Wolf, 1996: 11-15; Tugendhat, 2007: 40s), goza en nuestros días de una lozana vigencia, al menos en los escenarios antedichos. Hasta se ha llegado a hablar de una "filosofía contemporánea de la felicidad y el bienestar" (Badhwar, 2014: 5).

Así, no es de extrañar que muchos de los enfoques propuestos suelan venir acompañados, un poco ya está dicho, de preocupaciones metodológicas: los límites en este caso, y de acuerdo a una amplia mayoría de

1 Según la famosa advertencia de Sócrates a Trasímaco en el primer libro de la República, lo que está en juego dista de ser un asunto menor o trivial, pues se trata, ni más ni menos, del modo en que se ha de vivir (Platón, 1986: 352d). Para un análisis pormenorizado de la pregunta socrática, véase Williams, 1985: 1-21.

2 Todas las traducciones de citas correspondientes a textos escritos originalmente en alemán o inglés son de mi responsablidad: o bien he cotejado traducciones ya existentes al español con la versión original, mejorándolas en algunos casos; o bien he traducido la cita yo mismo, cuando no existe traducción.

3 Entre las monografías cabe destacar, entre otras, las de Crisp (2006), Kraut (2007), Haybron (2008), Tiberius (2008), Feldman (2010), Badhwar (2014), Alexandrova (2017) y Smuts (2017). 
autores y autoras, del tradicional análisis conceptual; la necesidad, según algunos, de un análisis reconstructivo; la pertinencia de conceptos metodológicos como "adecuación descriptiva" o "adecuación normativa"; la inclusión, y hasta qué punto, de la investigación empírica asociada a la llamada psicología positiva, entre otras preocupaciones (Sumner, 1996: 1-25; Haybron, 2008: 43-58; Tiberius, 2008: 3-18). Aunque no me detendré específicamente en ninguno de los puntos enumerados, también lo que sigue se inscribe en el marco de una reflexión metodológica en torno al tema de la vida buena, tal como este ha sido abordado desde hace unos treinta años en contextos, digamos, analíticos, tomando aquí el término "analítico" en un sentido extremadamente amplio y deliberadamente vago. Hacia el final, y aunque de un modo breve, haré el intento de confirmar la sospecha -improbable para algunos, ya de entrada verosímil para otros- de que lo metodológico suele estar determinado por, y a la vez determinar, cuestiones de contenido, al menos de índole general. ¿Es posible realmente separar del todo el modo en que algo se piensa de aquello que es pensado?

II.

Vienen al caso dos puntualizaciones preliminares, comenzando por una terminológica. Hoy por hoy, particularmente y de un modo creciente en el ámbito anglosajón, se habla de felicidad (happiness) para referir a un determinado estado mental, y de bienestar (well-being) en alusión a un cierto tipo de vida considerada buena para quien la vive. La diferencia crucial estriba en que mientras la felicidad, en cuanto condición psicológica, puede ser estudiada en términos predominantemente descriptivos, el bienestar se nos presenta por fuerza como un valor. La felicidad, así entendida, no será abordada en todo lo que sigue ${ }^{4}$. En cuanto a la noción de bienestar, resulta llamativa su cercanía semántica con la de vida buena. "Bienestar' significa vida buena, aquella vida que es buena para la persona de cuya vida se trata”, escribe Raz (2004: 269), cual vocero de numerosos

4 Pero importa precisar esta restricción. En más de una oportunidad, el uso del vocablo happiness y sus cognados sí apunta al bienestar humano y a la vida buena en general, por lo que Haybron (2008: 5) está en lo correcto al dejar constancia de un 'well-being' sense del término happiness, que por mi parte creo reconocer en textos como los de Annas (1993), McMahon (2006) y White (2006), entre otros. La observación vale aún más si se tiene en mente nuestro vocablo "felicidad" y el término equivalente en alemán: Glück. Por lo mismo, la restricción no se refiere a palabras, sino a temas: no se examinarán, por ejemplo, las disputas entre los tres enfoques predominantes acerca de la felicidad en cuanto estado mental (hedonismo psicológico, teoría de la satisfacción vital y teoría del estado emocional). Cabe agregar que el uso de happiness puede incluso fluctuar entre los dos sentidos distinguidos, como de hecho ocurre, pienso, en Nozick (1989). 
autores que usan ambos términos más o menos indistintamente ${ }^{5}$. En una línea no idéntica, pero parecida, cabe inscribir la noción de florecimiento humano (buman flourishing), de la que se valen una serie de autores ${ }^{6}$. Sin renunciar por completo a "bienestar" y "florecimiento humano", privilegiaré en todo lo que sigue el uso de la expresión "vida buena", por dos razones principales. Por un lado, porque en el presente contexto parece la más neutral de todas: "bienestar", lo mismo que sus equivalentes en alemán e inglés, remite no pocas veces - piénsese en estudios sociales o en el discurso público- a consideraciones de carácter empírico (Nussbaum \& Sen, 1993; Oyanedel \& Mella, 2014), mientras que "florecimiento humano" se asocia rápidamente a una concepción particular de la vida buena, una de corte eudemonista. Por otro lado, hablar de "vida buena" permite incorporar mejor la discusión alemana, en la que Woblbefinden o Woblergehen, los dos posibles equivalentes de well-being, presentan la desventaja de sugerir una actitud fundamentalmente pasiva (Wolf, 1999: 16) y poseen, acaso por lo mismo, una figuración bastante escasa.

La segunda puntualización es la siguiente: el valor que, según decía, resulta inherente al bienestar - y que el concepto favorecido exhibe ya en su nombre: vida buena- representa un particular tipo de valor conocido como prudencial. Se pregunta por una vida que es buena para aquel o aquella que lleva esa vida. La estructura formal "bueno para ..." distingue al valor prudencial respecto de, por ejemplo, el moral o el estético (Sumner, 1996: 20-25) ${ }^{7}$. En una línea análoga, Steinfath enfatiza que cabe interpretar la pregunta socrática en dos sentidos: uno sumamente amplio (¿cómo se debe vivir en general?) y uno relativo al bien del individuo que formula la pregunta (¿cómo se debe vivir por el propio bien?) (2013: 13-15). Con apoyo en tales distinciones, la cuestión de la vida buena se tomará aquí únicamente en su sentido prudencial, lo que constituye, entre otras cosas, una

5 Por cierto, el concepto de vida buena no necesariamente se agota en el de bienestar (Haybron, 2008: 36s). Valores morales (Annas, 1993; Seel, 1995; Bonete Perales, 2015), experiencias estéticas (Nehamas, 1998), así como el logro de una vida provista de sentido (Wolf, 2010; May, 2015), pueden ser considerados igualmente componentes de una vida buena. En vista, sin embargo, del encuadre metodológico de la presente reflexión, parece permitido, además de ventajoso, omitir la distinción entre bienestar y vida buena, con todo lo justificada y útil que pueda ser en otros contextos de discusión. Sobre el tema del sentido he desarrollado una propuesta en Fermandois (2015).

$6 \quad$ Kraut (2007: 3-8) ofrece una buena explicación y justificación de su uso.

$7 \quad$ Además del bien prudencial (lo que para alguien es bueno hacer) y el bien moral (lo que es bueno hacer dadas ciertas exigencias mutuas e incondicionales), Tugendhat distingue un bien adverbial (lo que cabe hacer peor o mejor), analizando las relaciones entre estos tres tipos de bien (2003: 65-74). 
licencia para dejar de lado la compleja y muy debatida relación entre moralidad y vida buena ${ }^{8}$. Por lo mismo, y siguiendo a Wolf (1999: 70s), en vez de la formulación estrictamente socrática: "¿cómo se debe vivir?", me orientaré en todo lo que sigue por la formulación "¿cómo se debería vivir?”, que apunta a lo aconsejable, más que a lo debido.

III.

De acuerdo a una clasificación propuesta inicialmente por Parfit (1984: 493-501), suelen distinguirse tres teorías del bienestar o la vida buena. 1) El hedonismo (llamado también hedonismo prudencial) concibe como vida buena aquella en la que predomina el placer frente al dolor. Junto a Brandt (1979) y Crisp (2006), un conocido representante actual es Feldman (2004 y 2010), quien propone una versión actitudinal de esta teoría (attitudinal hedonism), según la cual tanto el placer como el dolor no son meras sensaciones, sino actitudes frente a respectivos estados de cosas. 2) En las diferentes versiones de la teoría del deseo, como las desarrolladas en Griffin (1986) y Raz (1986), una vida buena aparece ligada fundamentalmente a la satisfacción de deseos o preferencias individuales, aunque con importantes restricciones epistémicas que dan pie a nociones como "deseo informado" (ver discusión en Sumner, 1996: 122-137). 3) De acuerdo a la teoría de la lista objetiva, existen factores -Finnis (2011) enumera los siguientes siete: vida humana, conocimiento, experiencia estética, juego y diversión, sociabilidad y amistad, razonabilidad práctica y, por último, religiónque, con independencia de si son deseados o no, constituyen en un sentido objetivo la vida buena de un ser humano?

Cada una de estas tres teorías presenta ciertamente tanto fortalezas como debilidades ${ }^{10}$. Pero más allá de cuestiones de contenido, me interesa fijar la mirada en un asunto metodológico relacionado con la clasificación misma (la que, dicho sea de paso, si bien es conocida en el ámbito alemán, no cumple en este un papel tan preponderante como en el anglosajón). La

8 Con lo cual, casi huelga decirlo, no cuestiono la posibilidad de que dicha relación sea particularmente estrecha, a tal punto que una vida buena desprovista de valores morales resulte improbable. Es, de hecho, lo que tiendo a pensar; solo que no me detendré aquí en la cuestión. En representación de una vasta literatura, véase: Annas (1993), Seel (1995) y Badhwar (2014).

9 Por cierto, esta clasificación tripartita no es la única: Haybron presenta una que contempla cinco teorías, o tipos de teorías, del bienestar (2008, p. 38); pero el hecho de que haya, como siempre, más de una posible tipificación no afecta en absoluto los propósitos de este texto (véase también Fletcher, 2016: 111-195).

10 Para una primera aproximación, véase Crisp (2017). 
clasificación estructura un debate entre teorías y al hacerlo presenta la indudable ventaja no solo de ordenar una discusión, sino también de promoverla. Al margen de tales méritos, empero, no pienso que el debate entre teorías sea - no en este caso, y sospecho que tampoco en otros- un asunto filosóficamente neutral. A la base de la presente reflexión se halla la convicción de que plantear las cosas como un debate entre teorías (tres o el número que sea) configura apenas un modo particular de abordar el tema de la vida buena y, probablemente, no el más fructífero. Ya el hecho de que se hable de teorías (theories) del bienestar o la vida buena debiera llamar nuestra atención. Ello responde en buena parte, es cierto, a un uso más bien laxo del término, además de bastante corriente, sobre todo en el medio anglosajón, un poco menos en el alemán; la palabra "teoría", mal que mal, puede ser reemplazada a menudo por términos, como "concepción" o "enfoque", libres de connotaciones que poco o nada vienen al caso (sistematicidad, carácter axiomático, predictibilidad, etc.). Pero tal como iremos viendo, nada de eso quita que se hallen en juego aquí pretensiones ni con mucho inocuas ${ }^{11}$. Mi intención es mostrar que existe una aproximación alternativa que no implica involucrarse derechamente en el debate y que de hecho lo soslaya por completo. Una aproximación, pues, indirecta: en vez de intentar abarcar la vida buena misma, suscribiendo o criticando argumentos a favor de una u otra concepción que de ella se proponen, resulta de mayor provecho centrar la mirada en contenidos más ceñidos o acotados, para intentar realizar a partir de su examen una que otra contribución de orden más general. En esta formulación tan amplia e indeterminada de la hipótesis radica la principal razón por la que hablo aquí de una aproximación y no de un método, noción, esta última, mucho más comprometedora en términos de precisión y rigor. En la misma línea, a nadie podrá sorprender que una aproximación indirecta no pueda ofrecernos más que indicios aproximados, fragmentarios y provisorios, en respuesta a la vieja pregunta socrática; solo que en estas materias, ya se irá viendo, tampoco parece recomendable aspirar a respuestas de índole más ambiciosa. Examinemos ahora más de cerca el carácter indirecto de la aproximación en cuestión.

11 La reflexión acerca de la vida buena que se desarrolla en el ámbito iberoamericano se halla -me parece importante consignarlo- libre de la crítica que aquí despunta. Los objetivos del presente artículo son, por un lado, mostrar una dificultad metodológica en la discusión anglosajona (y, en menor medida, en la alemana) y, por otro, esbozar una salida a tal dificultad. Si, con una mínima excepción, no hago referencias a la literatura sobre el tema surgida desde el contexto filosófico iberoamericano (u otros contextos), es únicamente debido a dichos objetivos. 
IV.

En diálogo crítico con las doctrinas rivales, cada una de las teorías antedichas elabora directamente una concepción de la vida buena. Temas que nadie dudaría en calificar como dimensiones de un buen vivir - la amistad, el amor, la confianza, una sana y profunda relación con la naturaleza, etc.suelen aparecer solo a título de ejemplos ilustrativos de tal o cual tesis sustantiva sobre la vida buena, no como objetos de estudio en sí mismos ${ }^{12}$. En absoluto quisiera negar que mediante tal procedimiento resulta posible acceder a planteamientos valiosos, como de hecho, pienso, ha ocurrido. Pero cabe también prestar oído a la sospecha, expresada por Tiberius (2008: 3), de que establecer el contenido o la naturaleza de la vida buena, en particular si se lo pretende hacer con cierto nivel de detalle a fin de que resulte interesante, representa una empresa cuyos resultados difícilmente serán materia de consenso. Por sí sola, esta observación no invalida el debate entre teorías - después de todo, la falta de consenso es diaria e irrenunciable realidad de todo quehacer filosófico-, pero sirve al menos de motivación para explorar un acceso alternativo, uno que se detenga más bien en aspectos particulares de una vida buena. En el libro Reflections on How We Live de Annette Baier (2009) detecto un buen modelo: las meditaciones de esta autora giran en torno a diversos temas (amistad, autoconocimiento, esperanza, honestidad, intimidad, confianza en sí mismo, entre otros), cuyo análisis y descripción generan un tipo de conocimiento de gran valor con respecto a lo que pueda constituir un logrado vivir. Ninguno de los ensayos que componen el libro se concentra derechamente en la vida buena considerada en sí misma.

En estrecha ligazón con lo anterior, las teorías de la vida buena ven su principal asunto en lo que se ha de alcanzar (ese logrado vivir, ese florecimiento humano), más que en el modo de alcanzarlo; en la meta o el objetivo, más que en el proceso. La distinción aparece en Tiberius, quien toma claro partido:

Defiendo un enfoque sobre cómo vivir centrado en la primera persona y basado en el proceso [process], como opuesto a una teoría impersonal de la vida buena basada en la meta [target]. Para ponerlo de otro modo, empezaremos con la pregunta "¿Cómo debería yo vivir?", en vez de preguntas como "¿Qué es una vida feliz?" o "¿Qué es una vida buena para un ser humano?”. (2008: 3)

12 Digo "suelen", porque el punto se aplica en menor medida al caso de las teorías de la lista objetiva. Con todo, estas teorías no parecen inmunes, como tampoco las otras, a las observaciones críticas presentadas aquí en las secciones V, VI y VII. 
En temáticas como las que Baier aborda en su libro cabe ver ciertamente componentes o incluso fases de aquel proceso, siempre contingente y nunca concluido, que constituye la búsqueda de una vida lograda y en el que Tiberius decide enfocarse. Más o menos explícitamente, ambas autoras parecieran llevar al ámbito de la metodología filosófica aquel sabio énfasis en el viaje o el camino que el poeta griego Kavafis celebra en su conocido poema Ítaca. La meta es el camino, el trayecto: lo que en más de una ocasión nos ha tocado como una verdad profunda (y en otras nos exaspera como cualquier tópico manoseado en exceso) se encuentra llamativamente ausente en el debate actual entre teorías de la vida buena.

Ahora bien, ya en este punto podría surgir una objeción: ¿acaso la propuesta de una aproximación indirecta no entra en conflicto con la plausible distinción entre la naturaleza de la vida buena y posibles fuentes de la misma? Cabría señalar lo mismo con respecto al tema de la felicidad: una cosa es la felicidad misma y otra muy distinta sus posibles causas, motivos o antecedentes. De un modo incluso más general, los orígenes (causas, antecedentes, etc.) de cualquier fenómeno no pueden ser confundidos con el fenómeno mismo. Autores como Sumner (1996: 16) y Haybron (2008: 66) suscriben esta diferenciación de un modo decidido. Sin embargo, una distinción que parece plausible no necesariamente lo es: desde una perspectiva pragmatista, cabe plantear, al menos como alternativa a tomar en cuenta, que una vida buena no es generada por, ni se manifiesta en, por ejemplo, nuestras experiencias de amor, confianza y amistad, sino que simplemente consiste en estas y otras experiencias (el punto semeja análogamente a un leitmoviv de la filosofía wittgensteiniana del lenguaje: la comprensión de una expresión lingüística, según el pragmatista que también era Wittgenstein, consiste en nuestras aplicaciones correctas de la misma, las cuales no son una mera manifestación externa de una supuesta comprensión interior previa). Intentar zanjar de antemano, esto es, con independencia de consideraciones ulteriores que vengan al caso, si conviene o no plegarse a la distinción entre aquello que una vida buena es y aquello en que una tal vida se manifiesta, parece caso perdido. Volveré, pues, sobre este asunto solo una vez que haya descrito y justificado algunas características de la aproximación recomendada. Tales características no se siguen sin más del carácter indirecto que le es distintivo y que he intentado esclarecer en la presente sección, sino que surgen más bien por oposición a ciertas pretensiones que se hallan a la base del actual debate entre teorías. En las tres secciones que siguen intentaré exponer el carácter problemático de dichas pretensiones. 
V.

En las teorías de la vida buena subyace, más o menos implícita, la premisa de que es posible reflexionar sobre el tema con neutralidad, sin que nos guíe alguna preferencia por tal o cual forma de vida. De un modo del todo explícito, la premisa es suscrita por Sumner (1996: 17s), quien ve en la neutralidad una de cuatro "virtudes cardinales de una teoría del bienestar" (1996: 18) ${ }^{13}$. Según Sumner, hemos de hacer todo lo posible por evitar favorecer algún tipo de bienes o alguna forma de vida. Aunque un autor o una autora se incline personalmente hacia tal o cual estilo particular de vida, su preferencia no podrá intervenir de modo alguno en su trabajo teórico. La misma condición teórica de dicho trabajo parece prohibirlo.

Sin embargo, ¿hasta qué punto se puede ser realmente neutral en estas materias? Y, por lo demás, “¿por qué pensar que la meta de la neutralidad es ella misma neutral?”, como pregunta Nozick (1981: 19) ${ }^{14}$. Pienso que la sospecha sugerida por interrogantes como estas es correcta y que la noción jamesiana de opción permite, además de sustentarla, darle mayor concreción. En su célebre ensayo La voluntad de creer, William James muestra de un modo persuasivo que en la aceptación de una creencia en cuanto verdadera no solo concurren consideraciones racionales, sino también lo que cabría denominar "factores emocionales". "Nuestra naturaleza no intelectual -sostiene James- ejerce decisiva influencia en nuestras convicciones" (2006: 10). Me sirvo de la etiqueta "factores emocionales" para aludir, como con una suerte de abreviatura, a una serie de términos empleados por el propio James: entre otros, "deseo", "preferencia sentimental" y "nuestra naturaleza volitiva". Esta última expresión es aclarada por el propio autor: "Cuando digo naturaleza volitiva, no se entienda voliciones deliberadas [...]: me refiero a factores de creencia tales como el miedo y la esperanza, el prejuicio y la pasión, la imitación y la presión del espíritu de casta y secta" (James, 2006: 8).

Ahora bien, según James, tales factores emocionales resultan ineludibles no ante una creencia cualquiera, sino que únicamente cuando nos ha-

13 Las restantes virtudes serían la fidelidad (adecuación descriptiva), la generalidad y la formalidad (Sumner, 1996: 10-19).

14 Con relación a una implausible neutralidad total se vuelve también relevante la cuestión de la historicidad de todo concepto de vida buena. Resulta difícil negar que el sentido mismo del término, y no solo aquello que este designa, ha ido sufriendo cambios a lo largo de la historia. En el medio filosófico alemán (véase, entre varios otros, Seel, 1995; Thomä, 2003; y Thomä, Henning \& Mitscherlich-Schönherr, 2011) parece existir bastante más conciencia respecto de este punto que en el anglosajón (aunque véase McMahon, 2006; y White, 2006). 
llamos frente a lo que él denomina una opción genuina. Dicho en pocas palabras, existe una opción genuina cuando se cumplen tres condiciones. Primero, hemos de hallarnos frente a hipótesis vivas, esto es, hipótesis que podamos realmente tomarnos en serio como eventuales creencias verdaderas o posibles cursos de acción correcta. La opción entre dos hipótesis que cumplan esa condición será viva, en la terminología de James (no lo sería en mi caso la opción entre viajar pasado mañana a un lugar relativamente cercano o viajar ese mismo día a la ciudad de Nuuk, en Groenlandia, y es que un viaje por estos días a Groenlandia no representa para mí una posibilidad real o genuina; se trata de una hipótesis muerta, como diría el autor). Segundo, una opción genuina requiere que no exista escapatoria a la elección entre las hipótesis: la opción ha de ser forzosa (no lo es, al menos en muchas ocasiones, la opción entre ir al cine o al teatro, ya que uno puede optar por quedarse en la casa, ir a un restaurante, etc.). Y, tercero, es preciso que en la elección se hallen en juego alternativas importantes e irrevocables: James habla ahora de una opción perentoria (no lo sería, no por lo menos en circunstancias normales, la opción entre un dulce o una galleta, porque en ello no nos va mucho). Pues bien, cuando nos hallamos ante una opción genuina - esto es: viva, forzosa y perentoria- no podemos sino operar en parte desde los factores que he llamado emocionales. Así lo demuestra ya el mero hecho de que aquello que hace de una determinada hipótesis una viva o una muerta no es una consideración puramente racional, sino un conglomerado de factores culturales o condiciones emocionales (sesgos, etc.). En conclusión, tenemos todo el derecho de optar entre proposiciones "donde quiera que se presente una opción genuina, que por su naturaleza no puede ser decidida en el campo intelectual" (James, 2006: 11). James piensa, en mi opinión correctamente, que en los ámbitos de la ética y la religión nos vemos enfrentados de un modo muy típico ante opciones genuinas. Así, su planteamiento nos conduce de un modo natural a reconocer los límites de la neutralidad cuando de temas existenciales se trata, como el de la vida buena. Siendo consecuentes, nos debería conducir asimismo a valernos del artículo femenino indeterminado ya en la mera designación de nuestro tema: una - y no la - vida buena, una vida buena entre otras. Nada de esto nos exime de argumentar ni implica ceder ante algún problemático relativismo. Sí permite, en cambio, apoyar dos planteamientos relacionados: en primer lugar, que la denominación "teorías de la vida buena" no resulta tan inocente como acaso pudo parecerlo en un primer momento, en la medida en que conlleva el compromiso con una neutralidad no exenta de dificultades; y, en segundo lugar, que el tratamiento de temas ético-existenciales parece requerir de una visión, digamos, más realista de los alcances de la argumentación filosófica. Este es justamente el tema de la siguiente sección. 
VI.

Las teorías de la vida buena se hallan, decíamos, en debate, lo que las lleva a privilegiar la argumentación de un modo unilateral. En la aproximación indirecta que aquí se expone, y siguiendo ahora ideas que Robert Nozick elabora en la instructiva introducción de Philosophical Explanations, el registro argumentativo puede y debe ser complementado por un registro explicativo. En vez de hacer descansar todo en la llamada fuerza del argumento, Nozick promueve una "modalidad de filosofía [que] busca explicaciones" (1981: 4ss), como lo insinúa ya el mismo título de su libro. Y es que cifrar todos los esfuerzos en la argumentación acaba conduciendo a la larga a una suerte de filosofía coercitiva o coactiva (coercive philosophy), odioso modo de filosofar que, pienso, dista de representar un modelo a seguir. Hay mucho de verdad en estas palabras:

¿Por qué intentan los filósofos forzar a otros a que crean ciertas cosas? ¿Es una forma agradable de comportarse con alguien? [...] La argumentación filosófica [...] no calza con la motivación original que nos llevó a estudiar filosofía o entrar en ella. Esa motivación es la perplejidad, la curiosidad, un deseo de comprender, no un deseo de producir uniformidad de creencias. La mayoría de la gente no quiere convertirse en una policía del pensamiento. (Nozick, 1981: 5 y 13)

Ahora bien, ¿en qué estriba, según el autor, la diferencia entre argumentar y explicar? En ambos casos opera ciertamente un mismo esquema básico de acuerdo al cual una proposición $p$ es inferida a partir de premisas $q, r, s .$. Pero no obstante dicho esquema -una "estructura abstracta", como la llama Nozick (1981: 13)—, común a la argumentación y la explicación, existen dos decisivas diferencias de orden pragmático. Por un lado, en un contexto explicativo la conclusión $p$ "debe ser conocida o al menos creída como verdadera" (1981: 13s), esto es, debe ser conocida o al menos creída de antemano. "Usted no se dispone a explicar algo que no tiene por verdadero" (1981: 14). En tal sentido, más que buscar acreditar la verdad de una creencia, el acto explicativo tiene por fin elaborar una posición coherente que deje entrever la mutua dependencia entre distintas creencias juzgadas como verdaderas; explicar es como armar un puzle en que distintas piezas encajan unas con otras. A la hora, en cambio, de argumentar o probar, lo que se intenta es mostrar que una creencia no considerada (aún) como verdadera, por un interlocutor y/o por uno mismo, efectivamente lo es. La segunda diferencia radica en lo siguiente: la pragmática del argumento o la prueba exige partir de premisas que ya sean objeto de conocimiento o al menos de creencia, mientras que en el caso de la explicación 
tal requerimiento no aplica. Cuando de explicar se trata, resulta perfectamente lícito introducir, en calidad de premisas, hipótesis explicativas $(q, r$, s...) que solo son creídas de un modo tentativo o que inicialmente no son creídas en absoluto, y a partir de las cuales se infiere, con un propósito explicativo, la conclusión $p$. Es el éxito de esta inferencia explicativa lo que puede luego conferir apoyo, un apoyo previamente ausente, a las hipótesis explicativas que han oficiado como premisas. Como corolario de esta segunda diferencia, el tono fundamental de la explicación será más bien el de una propuesta, una invitación a ver las cosas de determinado modo.

Las consideraciones metodológicas de Nozick se aplican cabalmente al tema de la vida buena. O para decirlo de otro modo: no estamos bajo obligación alguna de probar que, por ejemplo, experiencias satisfactorias de amor, confianza, amistad o contacto con la naturaleza representan, aunque cada una solo en un sentido parcial, una manera lograda de vivir la vida. Y el hecho de que no exista nada parecido a tal obligación se sigue, a su vez, de que en estos casos las pruebas tampoco parecen necesarias. ¿Es que necesitamos de pruebas para nuestro convencimiento de que la vía amorosa constituye una vía aconsejable? ¿No tenemos acaso que explicar esa realidad, más que argumentarla? De lo que se requiere en materias ético-existenciales es a menudo de más y más explicaciones. Hemos de explicitar nexos inferenciales entre las creencias pertinentes (en vez de acreditar alguna en particular), hemos de hacer visible una coherencia entre distintas experiencias de vida que muchas veces no resulta evidente de entrada.

Ahora bien, la metáfora coherentista del puzle o el rompecabezas, que subyace al planteamiento de Nozick, se me figura todavía un poco coercitiva; y lo mismo podría decirse del crucigrama o el sudoku. Mal que mal, cada vez que se acaba un puzle (o un crucigrama, o un sudoku), esto es, cada vez que las piezas (o las palabras, o los números) terminan de encajar mutuamente, el asunto ha concluido, y del modo más inequívoco y rotundo. Se ha logrado establecer que esa, y ninguna otra, es la forma en que las partes de un todo se acoplan entre sí. En temáticas filosóficas como la vida buena, el sentido de la vida o también la muerte, convendría pensar, a modo de analogía inspiradora, ya no en rompecabezas, crucigramas o sudokus, sino en el antiguo juego chino del tangram, en que con las mismas piezas es posible armar diversas figuras ${ }^{15}$. Y no es que sea solo posible, sino que es de lo que se trata. El tangram ofrece una buena imagen de la explicación filosófica, en los términos aquí propuestos - siguiendo, y en parte radicalizando, ideas de Nozick-, y subraya la necesidad de reflexionar ya

15 El tangram es un juego que consta de siete piezas (cinco triángulos, un cuadrado y un romboide) y que consiste en formar siluetas de figuras humanas, o de otro tipo, mediante esas siete piezas y sin solaparlas. 
no sobre la vida buena, sino sobre una vida buena entre otras, o sobre vidas buenas, así en plural. Como señala Kekes, "[n]o existe ninguna razón convincente para pensar que vidas buenas deban asumir una forma particular, y la historia, la etnografía y la literatura proveen de amplia evidencia al enfoque de que las vidas buenas tienen muchas formas" (2002: 9). Incluso a lo largo de una sola vida - la mía, por ejemplo, o la suya, lector o lectora- las cosas pueden cambiar, y tal cambio puede representar también un valor. Si a cierta edad manifestamos sensatez al privilegiar tal o cual tipo de actividad o actitud, a una edad distinta lo sensato puede ser jugar las fichas de otro modo. En cierto sentido al menos, es posible que los humanos vivamos varias vidas, más o menos buenas, más o menos malas.

VII.

El trabajo predominantemente argumentativo que caracteriza al debate entre teorías de la vida buena debe ser, pues, complementado por el ejercicio explicativo. Sin embargo, esto no resulta suficiente. Urge agregar un tercer e importante registro: el descriptivo. La reflexión filosófica sobre una vida buena se verá indudablemente beneficiada por un mayor esmero en la prolija descripción de experiencias relevantes. Dicha descripción no resulta menos importante que una sutil argumentación y su importancia es a menudo, creo, incluso mayor. Resultará apropiado y hasta necesario recurrir a veces al comentario de una película, la exégesis de un poema, alguna consideración histórica o biográfica, etc., pero no, como de hecho ocurre en la literatura filosófica que tengo en mente, a título una vez más de ejemplos meramente ilustrativos, esto es, a fin de cuentas, de ejemplos dispensables. No, la idea sería otra: que lo que importa comprender se halla en el ejemplo mismo, en su descripción.

La última observación se vuelve más concreta y plausible si nos detenemos ahora en la noción de descripción densa (thick description), tal como la ha elaborado el antropólogo Clifford Geertz (1973: 3-30). Geertz toma dicha noción de Gilbert Ryle, pero el alcance que logra otorgarle, en el marco de una reflexión acerca de la metodología de las ciencias sociales, debe mucho más al pensamiento tardío de Wittgenstein. La idea de la descripción densa puede ser explicada fácilmente mediante un ejemplo. Pensemos por un momento en una fotografía que muestra a un ser amado. De ese objeto en el mundo, la fotografía, cabe ofrecer distintas descripciones, todas ellas correctas. Puedo decir que se trata, primero, de un pedazo de papel fotográfico; segundo, de una fotografía impresa en la que se observa a un niño; tercero, de una fotografía impresa de mi hijo de ocho años saltando en un enorme lodazal; cuarto, de una fotografía impresa de mi hijo 
de ocho años, que él mismo, ya con mayor edad que en la foto, me regaló para un Día del Padre, a sabiendas de mi desagrado por esa institución social, y todo ello con el fin de que yo pusiera la fotografía en mi oficina y pudiese reírme a menudo de aquella vez en que él mismo, pero no yo, saltó y saltó en un enorme lodazal. Si tomamos ahora estas cuatro descripciones en el mismo orden en que las he presentado, Geertz diría que he ofrecido cuatro descripciones cada vez más densas del mismo objeto. Afirmar que se trata de un pedazo de papel fotográfico es brindar una descripción delgada (thin description), una exposición superficial del objeto casi vacía de interpretación y sentido. Por contraste, la cuarta descripción constituye obviamente la más densa (no solo la más larga). También es correcto mantener que conforme fui pasando de una descripción a otra, fui al mismo tiempo abondando mi comprensión del objeto, en el entendido de que existen diversos estratos de significado, cada vez más profundos, que mis descripciones fueron poniendo uno a uno al descubierto. Pues bien, lo que vale para la fotografía de mi hijo, vale también para cualquier manifestación simbólica: gestos, ritos, instituciones, leyendas, etc. La etnografía, según Geertz, no es sino descripción densa, pues se trata, como ya había sugerido Wittgenstein en sus comentarios a La rama dorada de Frazer, de describir, describir y describir, para finalmente agregar, casi suspirando, que la vida humana simplemente es asi ${ }^{16}$. Los textos acerca de la cuestión de la vida buena que me figuro como cercanos a un ideal serían textos sobre confianza, amor, amistad, esperanza, etc., que incluyeran una muy significativa cuota de descripción densa, lo que, de paso, los acercarían en buena medida a escritos de índole literaria ${ }^{17}$.

A la luz de la propuesta metodológica que la noción geertziana de descripción densa acarrea consigo, puedo retomar ahora el problema que permaneció abierto en la sección IV. Me refiero a la cuestión de si una vida buena es generada por nuestras experiencias de amor, confianza, amistad, etc., o si más bien no consiste justamente en estas y otras experiencias. De acuerdo a la primera alternativa, que podríamos calificar de realista, hemos de suscribir sin ambages la distinción entre aquello que una vida buena es y aquello en que una tal vida se manifiesta; la segunda alternativa, la pragmatista, nos aconseja el rechazo de tal distinción en el ámbito temático que nos ocupa. Debo confesar que no logro detectar en ninguna de las

16 La cita exacta es más escueta y dice así: “Aquí solo se puede describir y decir: así es la vida humana" (Wittgenstein, 1989: 31).

17 No puedo detenerme aquí en un análisis de la relación que una filosofía de la vida buena debiera mantener con la literatura, tanto en materias de forma como de contenido. Véase al respecto Wolf, 1991. 
consideraciones hechas hasta aquí nada semejante a un argumento contundente en favor de una de las dos opciones, opciones que, por lo demás representan interpretaciones radicalmente diferentes del tema mismo. Sin embargo, es posible plantear al menos lo siguiente: si la descripción densa representa una metodología atractiva para abordar la cuestión de una vida buena, entonces la opción pragmatista resulta la más apropiada. Esto, ya digo, dista de representar un argumento contundente a su favor. Sin embargo, brinda al menos una coherencia mayor a la propuesta del presente trabajo. La descripción densa y la interpretación pragmatista de nuestro tema se alimentan mutuamente.

Una reflexión filosófica acerca de una vida buena debiera asumir entonces no solo uno, sino varios registros - dijimos: argumentativo, explicativo y descriptivo-. Si ha de ser filosófica, deberá plegarse a la habitual dinámica de pedir y dar razones o argumentos. Pero si no quiere perder de vista precisamente la vida a la que dice referirse, el ejercicio argumentativo, aunque importante e irrenunciable, resultará del todo insuficiente. En su operar concreto, la aproximación indirecta que aquí se describe y recomienda habrá de conjugar prácticas (y técnicas) de argumentación, explicación y descripción. Ahora bien, quizá sea este el momento oportuno para despejar un posible malentendido del planteamiento general. Y es que la tesis de que existe una aproximación indirecta a nuestro tema que conjuga los tres registros en cuestión, presenta una ambigüedad: podría significar que la aproximación así descrita existe como una alternativa posible, o podría significar también que ha sido ya ensayada efectivamente. Lo que defiendo es esto último. Junto con el libro de Baier mencionado en la sección IV, existen muchos otros textos que son justamente reflejo de un acercamiento indirecto a la temática de una vida buena. Cuando en The Reasons of Love Harry Frankfurt (2004) explica y describe el fenómeno del amor como una forma específica en que alguien o algo nos puede importar o preocupar, no está sino hablando todo el tiempo, solo que básicamente de un modo oblicuo, acerca de una vida buena. Y habría que agregar, por cierto, varios otros textos y autores ${ }^{18}$. Si las reflexiones metodológicas aquí propuestas poseen algún valor, este no radica en la presentación de un enfoque - y mucho menos de un método- nuevo u original. Su eventual

18 John Kekes, uno de los pocos autores anglosajones contemporáneos con los que cabría asociar la aproximación indirecta menciona una serie de autores (entre otros, Aristóteles, Montaigne, Hume, Mill y Nietzsche, y más recientemente Murdoch, Oakeshott, Hadot y Nehamas) que se apartan del intento de "formular condiciones generales que hacen que vidas sean buenas" (2002: 8). Para dichos autores, como para el propio Kekes, "la indisponibilidad de una especificación completa o un estándar general [de lo que constituya una vida buena] no representa un fracaso, sino la consecuencia de la diversidad e individualidad de las vidas buenas" (2002: 9). 
función es otra y doble: la de explicitar las características de una aproximación al tema que se halla presente, aunque muchas veces de un modo más bien implícito, en no pocos autores, y la de criticar varios rasgos de la filosofía de la vida buena o el bienestar que se desarrolla actualmente bajo la figura de un debate entre teorías.

\section{VIII.}

Sostuve más arriba que el debate entre teorías, además de configurar apenas un modo particular de abordar el tema de la vida buena, probablemente no representa la vía más fructífera. Esto último dice también relación con una dificultad de fondo a la que se enfrenta el tratamiento directo y supuestamente neutral del tema que se observa en dicho debate. En la medida en que sea posible acreditar dicha dificultad como real, se estará a la vez reforzando la idea de que la aproximación indirecta no representa simplemente una posibilidad más, sino la más provechosa.

En un breve pasaje de su libro La filosofía y la cuestión de la vida buena, la filósofa alemana Ursula Wolf (1999) plantea que existe una diferencia estructural entre preguntar por aquello que sea bueno para la salud y aquello que lo sea para un buen vivir. Si en respuesta a la primera pregunta se nos aconseja, por ejemplo, la práctica de algún deporte, ello tiene sentido porque contamos de antemano con una idea más o menos clara de lo que sea la salud, esa salud que, según señala el consejo (probablemente correcto), resulta fomentada y conservada por algún deporte. Muy distinto es el caso de la segunda pregunta. Y es que no se halla para nada claro ni resuelto en qué pueda consistir ese buen vivir para cuyo logro se querría identificar alguna conducta o actividad. A diferencia del caso de la salud, ahora se busca un consejo para algo, en rigor, desconocido. Refiriéndose a la cuestión de la vida buena como "la cuestión práctica fundamental" [die grundsätrliche praktische Frage], Wolf expresa el punto en los siguientes términos: "lo particular y lo difícil de la cuestión práctica fundamental es precisamente que el fin no está en ella dado [...], sino que él mismo es todavía objeto de búsqueda" (1999: 71, mis cursivas).

Teniendo en mente, creo, el mismísimo punto de Wolf, Frankfurt lo radicaliza, poniendo en evidencia una irremediable circularidad inscrita en la pregunta misma de cómo se ha de vivir. Cito ahora a Frankfurt: "A fin de llevar a cabo una evaluación racional de algún modo de vivir, una persona debe primeramente conocer los criterios evaluativos que ha de emplear y saber cómo emplearlos" (2004: 24). En otras palabras, para hallarse en condiciones de siquiera comenzar a responder la pregunta por la vida buena, es preciso identificar aquellos criterios a emplear a la hora de evaluar distintas formas posibles de vivir. Pero, claro, la identificación de tales 
criterios implica haber ya respondido la pregunta de cómo vivir. Es por eso que Frankfurt califica esta pregunta como autorrefencial y los esfuerzos por hacer una indagación racional en torno a ella como "inexorablemente abocados al fracaso y a volver sobre sí mismos" (2004: 24). Según Wolf, la cuestión práctica fundamental encierra una dificultad. Según Frankfurt, se trata aquí, en rigor, de una imposibilidad.

Porque la pregunta por la vida buena coarta entonces de plano toda respuesta directa, no queda otra opción que la del camino indirecto, esto es, el de plantearse otras preguntas que de algún modo refieran a ella. Que una pregunta refiera a otra es precisamente la figura que usó Kant para dar cuenta de una importante diferencia existente entre las cuatro interrogantes de la filosofía que célebremente identificó en su Lógica. Como se recordará, la cuarta interrogante, la pregunta antropológica de qué sea el ser humano es destacada por Kant respecto de las otras tres. La pregunta epistemológica: “¿qué puedo conocer?”, la ética: “¿qué debo hacer?” y la religiosa: "¿qué me cabe esperar?" se refieren, dice Kant (sich beziehen auf), a la cuestión antropológica (1982: 447s). Comentando el mismo pasaje, Tugendhat hablará de "apuntar" (verweisen) (2007: 36). Pienso que la pregunta por la vida buena, como también la pregunta por el sentido de la vida, se mueve en ese mismo nivel último propio de la pregunta antropológica, según Kant. Se trata de preguntas que configuran el horizonte al que debieran apuntar, el marco en el que debieran estar siempre inscritas, otras indagaciones filosóficas $-\mathrm{y}$ en cierta medida todas-. Estas preguntasmarco o preguntas-horizonte no pueden recibir respuestas directas, sino solo indirectas (e incompletas, y provisorias). Nunca he logrado saber si debemos reconocer en la filosofía solamente una pregunta-marco, ni tampoco si, tratándose de varias, cuántas y cuáles serían. Pero la pregunta por una vida buena, la pregunta por el sentido de la existencia y la pregunta antropológica se me figuran al menos serias candidatas y, quién sabe, modulaciones de un mismo interrogar fundamental al que solo podemos aproximarnos de un modo indirecto o colateral.

IX.

Situando lo planteado hasta aquí en un contexto histórico-filosófico más amplio, cabría sostener que la disputa entre, por un lado, el establecimiento de la cuestión de la vida buena como objeto de una teorización explícita y directa y, por otro, la prescripción kantiana de esa misma cuestión en cuanto posible tema de una filosofía que responda a estándares argumentativos suficientemente rigurosos, se revela, a la luz del enfoque aquí propuesto, como una falsa alternativa. Pace Kant, de la vida buena sí cabe discurrir filosóficamente; pace los teóricos actuales, conviene hacerlo 
principalmente de un modo indirecto. Es más, a la base del dudoso dilema parecieran estar operando, en ambos bandos, una serie de supuestos relativos al proceder filosófico, como la aspiración a una completa neutralidad o la unilateral prerrogativa concedida a la actividad de argumentar, que bien pueden ser cuestionados.

Por otro lado, estamos también ahora en condiciones de confirmar la sospecha de que una reflexión metodológica nunca se reduce al delineamiento de un camino a seguir, sino que suele influenciar asuntos generales de contenido y estar al mismo tiempo inspirada en ellos; como se sugirió al final de la primera sección, el modo en que algo se piensa no pareciera ser completamente separable de aquello que se piensa. Si tuviera que resumir el planteamiento general de estas reflexiones en una clave menos metodológica y más sustantiva, diría que quizá no importa tanto lo que una vida buena sea en sí misma, sino cómo sea todo aquello que pueda considerarse, con cierto grado de plausibilidad, una contribución a tal vida. Y es que una vida buena, por tratarse también de algo así como una atmósfera - o una cierta luz, o una cierta mirada - tiende inevitablemente a escapársenos cada vez que la queremos fijar o determinar conceptualmente. Hay una lograda frase que escribió alguna vez Michael Dummett comentando el pensamiento de Wittgenstein: "Una mirada límpida —dijo Dummettno es a su vez un objeto visible" (1978: 439). Si no estoy equivocado, una vida buena se parece justamente mucho más a una mirada límpida que a un objeto visible.

\section{REFERENCIAS}

Alexandrova, A. (2017). A Philosophy for the Science of Well-being. New York: Oxford University Press.

Annas, J. (1993). The Morality of Happiness. New York: Oxford University Press.

Badhwar, N. (2014). Well-Being. Happiness in a Worthwhile Life. Oxford: Oxford University Press.

Baier, A. C. (2009). Reflections on How We Live. Oxford: Oxford University Press.

Bonete Perales, E. (Ed.) (2015). Tras la felicidad moral. Madrid: Cátedra.

Brandt, R. B. (1979). A Theory of the Good and the Right. New York: Oxford University Press.

Crisp, R. (2017). Well-Being. The Stanford Encyclopedia of Philosophy (Fall 2017 Edition), Edward N. Zalta (ed.), URL = <https://plato.stanford.edu/archives/fall2017/entries/well-being/>

Crisp, R. (2006). Reasons and the Good. Oxford: Clarendon Press.

Dummett, M. (1978). Can Analytical Philosophy be Systematic, and Ought it to Be? En M. Dummett, Truth and other enigmas (pp. 437-458). Cambridge, Mass.: Harvard University Press (La verdady otros enigmas. Madrid: Fondo de Cultura Económica, 1980). 
Feldman, F. (2010). What is this Thing Called Happiness? Oxford: Oxford University Press.

Feldman, F. (2004). Pleasure and the Good Life. Oxford: Clarendon Press.

Fermandois, E. (2015). Ambigüedad, disolución y latencia: sobre el sentido de la vida. Isegoría. Revista de filosofía moral y política, (53), 515-536.

Finnis, J. (2011). Natural Law and Natural Rights. (2nd edition). Oxford: Clarendon Press.

Fletcher, G. (Ed.) (2016). The Routledge Handbook of the Philosophy of Well-being. London: Routledge.

Frankfurt, H. (2004). The Reasons of Love. Princeton: Princeton University Press (Las razones del amor. El sentido de nuestras vidas. Barcelona: Paidós, 2004).

Geertz, C. (1973). Thick Description: Toward an Interpretive Theory of Culture. En C. Geertz, The Interpretation of Cultures. Selected Essays (pp. 3-30). New York: Basic Books (Descripción densa: hacia una teoría interpretativa de la cultura. En C. Geertz, La interpretación de las culturas. Barcelona: Gedisa 2000, pp. 19-40).

Griffin, J. (1986). Well-Being. Oxford: Clarendon Press.

Haybron, D. M. (2008). The Pursuit of Unhappiness. The Elusive Psychology of WellBeing. Oxford: Oxford University Press.

Hoesch, M., Muders, S. \& Rüther, M. (Eds.) (2013). Glück - Werte - Sinn. Metaethische, ethische und theologische Zugänge zur Frage nach dem guten Leben. Berlin: de Gruyter.

James, W. (2006). The Will to Believe and Other Essays in Popular Philosophy. New York: Cosimo (La voluntad de creer. Barcelona: Marbot Ediciones, 2009).

Kant, I. (1982). Logik. En I. Kant, Werkausgabe Band VI. Frankfurt a. M.: Suhrkam (Lógica. Madrid: Ediciones Akal).

Kekes, J. (2002). The Art of Life. Ithaca/London: Cornell University Press.

Kraut, R. (2007). What is Good and Why. The Ethics of Well-Being. Cambridge/London: Harvard University Press.

May, T. (2015). A Significant Life. Human Meaning in a Silent Universe, Chicago/London: The University of Chicago Press.

McMahon, D. M. (2006). Happiness: A History. New York: Grove Press.

Nehamas, A. (1998). The art of living: socratic reflections from Plato to Foucault, Berkeley: University of California Press (El arte de vivir. Reflexiones socráticas de Platón a Foucault. Valencia: Pre-Textos, 2005).

Nozick, R. (1989). The Examined Life. New York: Simon and Schuster (Meditaciones sobre la vida. Barcelona: Gedisa, 1992).

Nozick, R. (1981). Philosophical Explanations. Cambridge, Mass.: The Belknap Press of Harvard University Press.

Nussbaum, M. \& Sen, A. (Eds.) (1993). The Quality of Life. Oxford: Clarendon Press.

Oyanedel, J. C. \& Mella, C. (Eds.) (2014). Debates sobre el bienestar y la felicidad. Santiago: RIL editores.

Parfit, D. (1984). Reasons and Persons. Oxford: Clarendon Press.

Platón (1986). Diálogos IV. República. Madrid: Gredos. 
Raz, J. (2004). The Role of Well-being. Philosophical Perspectives, 18, 269-294.

Raz, J. (1986). The Morality of Freedom. Oxford: Clarendon Press.

Seel, M. (1995). Versuch über die Form des Glücks. Frankfurt a. M.: Suhrkamp.

Seel, M. (1991). Die Wiederkehr der Ethik des guten Lebens. Merkur, 45(502), 42-49.

Smuts, A. (2017). Welfare, Meaning, and Worth. London: Routledge.

Steinfath, U. (2013). Werte und Glück. Dimensionen der Frage nach dem guten Leben. En M. Hoesch, S. Muders \& M. Rüther (Eds.), Glück - Werte - Sinn. Metaethische, ethische und theologische Zugänge zur Frage nach dem guten Leben. (pp. 13-33). Berlin: de Gruyter.

Steinfath, U. (ed.) (1998). Was istein gutes Leben? Philosophische Reflexionen. Frankfurt a. M.: Suhrkamp.

Sumner, L. W. (1996). Welfare, Happiness, and Ethics. Oxford: Oxford University Press.

Thomä, D. (2003). Vom Glück in der Moderne, Frankfurt a. M.: Suhrkamp.

Thomä, D., Henning, C. \& Mitscherlich-Schönherr, O. (Eds.) (2011). Glück. Ein interdisziplinäres Handbuch. Stuttgart: Metzler.

Tiberius, V. (2008). The Reflective Life. Living Wisely with our Limits. Oxford: Oxford University Press.

Tugendhat, E. (2007). Anthropologie statt Metaphysik. München: Beck (Antropología en vez de metafísica, Barcelona: Gedisa, 2008).

Tugendhat, E. (2003). Egozentrizität und Mystik. Eine anthropologische Studie. München: Beck (Egocentricidad y mística. Barcelona: Gedisa, 2009).

White, N. (2006). A Brief History of Happiness. Oxford: Blackwell.

Williams, B. (1985). Ethics and the Limits of Philosophy. London: Fontana Press (La ética y los límites de la filosofía. Madrid: Cátedra, 2016).

Wittgenstein, L. (1989). Bemerkungen über Frazers Golden Bough. En L. Wittgenstein, Vortrag über Ethike und andere kleine Schriften (pp. 29-46). Frankfurt a. M.: Suhrkamp. (Observaciones sobre La Rama Dorada de Frazer. Santiago: Ediciones Tácitas, 2016).

Wolf, S. (2010). Meaning in Life and Why It Matters. Princeton: Princeton University Press.

Wolf, U. (1999). Die Philosophie und die Frage nach dem guten Leben. Reinbek bei Hamburg: Rowohlt. (La filosofía y la cuestión de la vida buena. Madrid: Síntesis 2002).

Wolf, U. (1996). Die Suche nach dem guten Leben. Platons Frühdialoge. Reinbek bei Hamburg: Rowohlt.

Wolf, U. (1991). Kunst, Philosophie und die Frage nach dem guten Leben. En F. Koppe (Ed.), Perspektiven der Kunstphilosophie. Texte und Diskussionen (pp. 109-132). Frankfurt a. M.: Suhrkamp. 